\section{América Latina: cidades, memórias e esquecimentos sob o olhar da literatura}

\section{Latin America: cities, memories and forgetfulness under the eyes of literature}

\section{Resumo}

Este artigo formula algumas reflexões sobre a associação da história com a literatura. Estabelecemos alguns nexos com trabalhos literários de autores latino-americanos do século XX. Nas páginas desses romances latino-americanos desfilam os expoentes de toda uma estrutura de dominação: políticos, velhos aristocratas, oportunistas recém-chegados, fazendeiros truculentos, funcionários públicos subservientes, advogados venais, representantes do capitalismo local, dominados e dominantes. Mostram-nos os vários escritores latino-americanos as ditaduras na sua insanidade grotesca, as repressões cruentas que fazem emergir os movimentos sociais populares. Estão presentes as turbulências do real e imaginário, utilitário e mágico, da dúvida e perplexidade, memória e esperança, do esquecimento e da desesperança, do espelho e labirinto.

Palavras-chave: História, Literatura, Espelho, Labirinto, América Latina.

\section{Abstract \\ This article proposes some reflections about the association between history and literature. We have established some links with literary works written by Latin American authors of the twentieth century. In the pages of these Latin American novels the exponents of a whole structure of domination are paraded: politicians, old aristocrats, opportunist newcomers, truculent farmers, subservient civil servants, venal lawyers, representatives of local capitalism, dominated and do- minant ones. The various Latin American writers show us dictatorships in their grotesque insanity, the bloody repressions that allow popular social movements to emerge. They outline the turbulences of the real}

Prof. Dr. $^{a}$ Yvone Dias Avelino

Doutorado em História

Econômica pela

Universidade de São Paulo (1973) e Pós-Doutorado em História pela PUC-SP (1989).

É titular no Departamento de História da PUC-SP, onde atua como docente desde 1971. Integra as comissões consultivas e editorias das seguintes revistas: Oralidades - Revista de História Oral (USP);

Práxis - Revista Eletrônica de História e Educação

(Universidade Jorge Amado, Salvador, BA); Projeto História (PUC-SP); Aurora Revista Eletrônica de Arte, Mídia e Política (PUC-SP). Coordena o NEHSC da PUC$\mathrm{SP}$, existente há mais de vinte anos. É editora da revista Cordis - Revista Eletrônica de História Social da Cidade - disponível em: <http:// revistas.pucsp.br/cordis $>$.

E-mail: yvonediasavelino@ uol.com.br 
and imaginary, utilitarian and magical, doubt and perplexity, memory and hope, forgetfulness and hopelessness, mirror and labyrinth.

Keywords: History, Literature, Mirror, Labyrinth, Latin America.

\section{Introdução}

Pretendemos, neste artigo, estabelecer algumas reflexões sobre a associação da história com a literatura, ou seja, a forma de utilizar esta última como fonte ao historiador. Nesse sentido, buscamos estabelecer alguns nexos com trabalhos literários de autores latino- $a-$ mericanos do início e meados do século XX.

Ao revisitarmos a diversidade de problemas, temas, olhares, disciplinas, saberes e registros que constituíram a América Latina desde a conquista ibérica até os dias atuais, colocamo-nos enquanto historiadores na premissa de estabelecer um diálogo intenso e ininterrupto entre as possibilidades da relação história e literatura neste continente.

Como latino-americanos, sobretudo oriundos do Brasil, observamos um problema na relação com os meios intelectuais, artísticos e políticos brasileiros: em sempre voltarem os seus olhares à Europa, em um primeiro momento e, no decurso do século XX, aos Estados Unidos, quase que negando e virando as costas ao nosso próprio continente latino. O nosso olhar foi seduzido para deslumbrar essas realidades latino-americanas, díspares, tão importantes e significativas no processo de sua história. Neste, é recente o encantamento do encontro dos brasileiros com as grandes representações culturais da latinidade americana.

Se pensarmos em envolvimentos mais expressivos, encontraremos problemas, buscas de entendimentos e comparações que percorrem a historiografia e produção literária. Exemplos disto são os textos produzidos por José Veríssimo, Manuel Bonfim e até José de Alencar, com seu Anagrama de Iracema. Mesmo na Universidade, os estudos sistemáticos da literatura latino-americana despontam tar- diamente, sendo exceções algumas das quais, como a PUC-SP e USP, que conhecemos mais de perto. Até a década de 1970, tal assunto foi pouco significativo no cômputo geral da produção acadêmica nacional.

As representações e o imaginário político das oposições e organizações revolucionárias das décadas de 1960 e 1970 na América Latina foram marcos importantes na trajetória desses estudos históricos, da produção e crítica literária, além da produção cinematográfica. Tais representações encontraram as suas expressões nas comunidades de exilados, em seus percursos internacionais e nas repercussões na mídia censurada, no meio acadêmico ávido de um saber competente, engajado e transformado.

É no exílio e nas radicais mudanças das formas de produção do conhecimento sobre temáticas latino-americanas que nos encontramos e buscamos entender os mecanismos que nos levaram ao isolamento, deslocamento do olhar, distanciamento das questões e dos problemas comuns, bem como das particularidades de cada formação social, geográfica e política nos âmbitos da memória e do esquecimento.

No contexto socioeconômico da América dita Latina, as suas preocupações políticas, a sua história, as suas reivindicações, tentativas de mudanças sociais e o seu processo de formação - inclusive étnica - são quase desconhecidos por muitos, pelos universitários, pela elite intelectual, que sabe o que se passa no mundo europeu e norte-americano - e não em nosso continente. Quando o nome América originalmente apareceu, identificado em um mapa, a parte do Globo que viria a ser chamada de Novo Mundo configurava uma unidade geográfica sem fronteiras. Mais tarde, os conhecimentos acerca de seus acidentes geográficos, seu clima e sua população demonstraram a extrema diversidade do Continente. A evolução das sociedades americanas veio contribuir, destacando e aprofundando as suas diferenças, apesar das semelhanças de seus processos históricos, de modo que um dos fatores de maior 
diferenciação é a diversidade étnico-cultural das inúmeras sociedades americanas.

Refletindo sobre as relações entre história e literatura, no espaço da América Latina buscamos ambientes de reflexões de literatos que a olharam e, por meio de seus escritos, iluminam o universo da história.

A historiografia apela à literatura atual como mais um registro do real, um instrumento para a sua compreensão ou, ainda, como a sua metáfora epistemológica. O interesse do historiador em usar a literatura como fonte às suas pesquisas é, grosso modo, recente. Nos idos da década de 1980, literatura e história se fundiram como áreas de interesses comuns e, ao mesmo tempo, distintos. Caminho importante aos saltos qualitativos dados pela historiografia contemporânea nessa relação, o historiador não pode encarar a obra literária como mero veículo de conteúdo, pois o valor do texto literário não está propriamente na confrontação que deste se pode fazer com a realidade exterior, mas na maneira como essa realidade é abordada, aprofundada, questionada, recriada - trata-se de encarar a literatura não como reflexo, mas como refração, desvio, tais como nos narram os autores do texto $O$ bosque sagrado e o borrador (AVELINO et al., 1992, p. 8).

Como representação que é, a arte ilustra os valores de uma cultura, e não se presta a fornecer a confirmação de um saber que poderia adquirir de outras formas como, por exemplo, na pesquisa histórica. Ademais, apresenta princípios e leis diferentes dos da realidade exterior já inventariada. O artista está sempre ultrapassando os sistemas de classificação aos quais uma sociedade confirmou as suas representações provisórias do mundo. Logo, a arte não reproduz a realidade exterior, mas a transforma, exprimindo o que nesta está reprimido ou latente.

A obra literária eficaz que age sobre os seus leitores é aquela que dramatiza as contradições e as exacerba, levando-as às últimas consequências. Ou seja, representa-as e, oferece, assim, um princípio de resposta às perguntas ainda não claramente formuladas. Libera possibilidades subjacentes a certas situações, joga com essas possibilidades, dá vida, buscando explorar as virtudes inerentes a uma época.

As obras literárias que melhor traduzem os movimentos sociais e históricos não são as que retratam de forma escrupulosamente exata os acontecimentos anteriores. São as que exprimem aquilo que falta a um grupo social -e não aquilo que possui plenamente.

Outrossim, a literatura diz ao historiador sobre a história que não ocorreu, acerca das possibilidades que não vingaram, sobre os planos que não se concretizaram. Pode-se, portanto, pensar em uma história dos desejos não consumados, dos possíveis não realizados, das ideias não vingadas, tal como nos apontou o historiador Sevcenko (1995).

Ocupa-se o historiador, portanto, da realidade, enquanto o escritor é atraído pela possibilidade. Cabe ao historiador, assim, captar esse excedente de sentido embutido no romance.

O método para Lacapra (1991, p. 107-124) é o de se fazer uma fusão entre texto e contexto, ou seja, usar a linguagem para interpretar contextos - não no sentido positivista, mas como representação de uma experiência histórica. É o caminhar para se apossar de como se apresentou dada realidade.

A história é um caleidoscópio de ações humanas, um romance verdadeiro. Simplifica, seleciona, organiza. Para Veyne (1995), o que distingue um livro de história de um romance, isto é, a narrativa histórica da narrativa de ficção, é que o primeiro tem o seu suporte na realidade exterior, com existência concreta e autônoma. Logo, dispensa artifícios discursivos e estéticos para ser valorizado. A história é, assim, uma narrativa verídica, cujos acontecimentos se submetem ao critério da verdade; ao contrário do discurso ficcional, que é uma questão de verossimilhança.

Ainda nessa comparação, podemos afirmar que a história é um discurso que visa à realidade teórica e científica, não ignorando o caráter 
de relatividade da verdade histórica e toda subjetividade que comporta a elaboração desse conhecimento. Já o texto literário tem como objetivo fundamental a produção da realidade estética, o que não lhe exclui ter relações com a realidade objetiva, ou seja, com tudo aquilo que the é exterior e, de certa forma, que o envolve.

Os romances históricos, como afirma Gilberto Freyre (1961), transmitem

[...] uma verdade histórica através da verossimilhança novelesca, tem o poder de fazer a carne voltar a ser verbo, sem o verbo perder o gosto, ou a cor, ou o cheiro, ou a forma da carne, imagem que nos parece bastante significativa do poder de re-criação da obra literária e das suas relações com a realidade que ela representa.

Assim, a transformação de elementos não literários em expressão estética é outra maneira de olhar o objeto, uma nova forma de relação com o real.

Discurso histórico e narrativa literária são formas distintas de narrativa, afinal, apresentam modos de contato, relacionam-se com a realidade exterior de maneiras diferentes, porém, complementares. Ambos os meios correspondem a imagens dessa realidade, submetendo-se às exigências do discurso e, portanto, podendo apresentar deformações, fragmentações e/ou distorções, formas parciais de conhecimento; de modo que a literatura aprofunda intuitivamente o conhecimento humano, enquanto a história o analisa cientificamente - formas complementares de expressão da realidade do conhecimento.

Partindo-se da ótica da interdisciplinaridade, a tendência moderna é destruir as fronteiras que foram construídas no conhecimento tradicional. Ciência e arte, ficção e verdade aproximam-se à medida que a narrativa historiográfica vai surgindo, em contraposição ao declínio da história científica generalizante, colocando em dúvida a questão da veracidade, chegando-se a uma natureza dual da história Ciência e arte, simultaneamente (SOUSA, 2001).
Para Veyne (1995), o historiador passou a agir como um romancista ao tecer um fio de narração aos fatos escolhidos, diferenciando-se do verdadeiro romancista, enquanto relator de eventos reais, acontecidos, em contraposição a uma narrativa substancializada na imaginação acerca do mundo sentido.

Concebendo o texto literário como sistema de signos, tal como nos aponta a vertente da Semiótica peirceana, cabe ao historiador interrogá-lo intensamente em busca de sua interação e interpenetração com as estruturas sociais, utilizando-o como cunha para penetrar nas relações entre o homem e a natureza, o homem e seu produto, e entre homem e homem. A literatura faz aquilatar a relação e o nível das tensões existentes na sociedade e, nesse campo, frequentemente a historiografia tradicional nos fica devendo - se nos atermos apenas a qual. A literatura nos apresenta as expectativas do vir a ser, o testemunho das possibilidades que não vingaram, dos planos que não se concretizaram.

Já o historiador se debruça sobre o texto literário em busca de signos que apontem ao passado, cabendo ao qual os representar e reapresentar, alvejando-os pelo ângulo das práticas sociais da época, tal como aconselha Foucault citado por Veyne (1982), resgatando-os do limbo da abstração para apresentá-los na sua objetividade concreta, recuperando os elementos de sua totalidade.

Assim também se apresenta a vertente semiológica, então baseada na linguística e intro-

Charles Sanders Peirce (1839-1914), cientista, matemático, historiador, filósofo e lógico norte-americano é considerado o fundador da moderna Semiótica. Graduou-se com louvor pela Universidade de Harvard em Química, fez contribuições importantes nos campos da Geodésia, Biologia, Psicologia, Matemática e Filosofia. Peirce, como diz Maria Lúcia Santaella Braga (2001), foi um "Leonardo das Ciências Modernas". Uma das marcas do pensamento peirceano é a ampliação das noções de signo e, consequentemente, de linguagem. Peirce "[...] foi o enunciador da tese anticartesiana de que todo pensamento se dá em signos, na continuidade dos signos [...]", do diagrama das $\mathrm{Ci}$ ências; das categorias; do pragmatismo. 
duzida por Saussure, ${ }^{2}$ ao discorrer de uma ilusão referencial do efeito realidade, criada pelo discurso histórico, cuja existência é linguística, é signo, discurso; propriedade fundamentalmente literária. ${ }^{3}$ Nessas expressões, utilizadas por Roland Barthes (1972), desfazem-se as fronteiras entre história e literatura, uma e outra ofertando possibilidades do reconhecimento do social, revelando sentimentos incorporados nos feitos e fazeres do ser humano, signos identificadores do realizar.

Estabelecer a literatura como uma fonte para o historiador, ao lado de tantas outras novas e das tradicionais significa buscar um método, pois trata-se de uma linguagem específica, onde esse pode operar apenas por meio de instrumentos próprios, para uma leitura possível da história. As vertentes da Semiótica oferecem ao historiador um diálogo na construção desse método - Cardoso e Vainfas (1997)

Ferdinand de Saussure (1857-1913) foi um linguista filósofo suíço cujas elaborações teóricas propiciaram o desenvolvimento da Linguística enquanto Ciência e desencadearam o surgimento do estruturalismo. Além disso, o pensamento de Saussure estimulou muitos dos questionamentos que compareceram na linguística do século XX. Saussure estudou Física e Química, mas continuou fazendo cursos das gramáticas grega e latina. Por fim, convenceu-se de que a sua carreira estava nos estudos da linguagem e ingressou na Sociedade Linguística de Paris. Entendia a Linguística como um ramo da Ciência mais geral dos signos, que propôs ser chamada de Semiologia. Graças aos seus estudos e ao trabalho de Leonard Bloomfield, a Linguística adquiriu autonomia, de modo que o seu objeto e método próprios passaram a ser delineados. Ademais, os seus conceitos serviram de bases ao desenvolvimento do estruturalismo no século XX (CARVALHO, 2003).

3 A tradição semiótica de Peirce se difere da semiológica proposta por Saussure porque a Semiótica não tem como princípio ou quase exclusiva inspiração a fala e língua humanas; vê na semiose um processo muito mais vasto e fundamental, envolvendo o Universo como físico no processo da semiose humana, fazendo desta uma parte da semiose da natureza. Assim, Semiótica e Semiologia constituem duas tradições ou dois paradigmas, o que tem até certo ponto prejudicado o desenvolvimento contemporâneo, por existir dentro do qual em condições sociológicas de oposição. Todavia, tal dualidade não é apenas desnecessária logicamente, mas depende, para o seu sustento, de uma sinédoque perversa pela qual a parte é tomada erradamente pelo todo. A Semiótica forma um todo do qual a Semiologia é uma parte (DEELY, 1990). apontam a necessidade da interdisciplinaridade na medida em que o material do historiador é sempre a linguagem.

O texto literário é um valioso instrumento, que faz mergulhar a sensibilidade do historiador em um mundo mágico, em uma super-realidade, em uma mescla de sonhos, expectativas que vão além da esperança em si. É uma possibilidade para identificar o imaginário e as representações coletivas dos grupos sociais envolvidos nos acontecimentos e na formação do processo histórico.

A busca do sentido do texto pode ser a procura da face oculta da história. Por meio do discurso literário, penetra-se no mundo das consciências, no imaginário, nas representações coletivas na medida em que estas justificam, sublimam, reforçam e condicionam as práticas sociais do indivíduo enquanto protagonista dos acontecimentos e formador do processo histórico. A pesquisa dessas práticas e relações iluminadas através do texto literário é uma tentativa e uma proposta metodológica para resplandecer a sua aura, os seus contornos opacos e cuja eficácia será aferida pelo trabalho minucioso do historiador.

História é uma constelação de forças contraditórias em configurações pluridimensionais permanentes. Possui um caráter abrangente, onde o historiador deve captar o real. Tarefa difícil, porque tudo é história e a todos impregna. Assim, a riqueza interpretativa que podemos resgatar na literatura é uma valiosa contribuição ao trabalho do historiador, enquanto percepção de relação e tensão entre estruturas históricas e literárias que há muito permeiam o pensamento humano. Em Aristóteles ([20--?]): "O historiador e o poeta se distinguem um do outro porque um escreve o que aconteceu, e o outro, o que poderia ter acontecido". Em Cervantes (2005): "O poeta pode contar as coisas não como foram, mas como deviam ser, e o historiador há de escrevê-las não como deviam ser, e sim, como foram".

Como toda manifestação do homem, a literatura é marcada por seu tempo, representando 
os ideais, as aspirações, necessidades e esperanças de uma época. Assim, o imbricamento de história e literatura se dá em níveis complexos e profundos, pois se engendram na tentativa de entendimento da dinâmica do ser e, ao mesmo tempo, de um documento de época. Há entre ambas uma relação intertextual e dialógica. Literatura reflete o real, refratando-o, e é na refração que se encontram as angulações que interessam ao historiador, como nos afirma Eleutério (1987).

Tanto Eleutério (1987) como Sevcenko (1995) desempenharam magistralmente o ofício de historiadores, desvendando os caminhos para que se perceba de que forma os fenômenos históricos se reproduzem no campo da literatura e podem ser captados pelo historiador. Ambos leram a história no ato simultâneo de ler a literatura - reproduzindo pelo avesso o movimento de quem fez história fazendo literatura.

\begin{abstract}
A ficção invade a História, a ficção infringe a História, a ficção dramatiza a História. Não foi, portanto, o simples prazer de reconstituir a História que levou Malraux a escolher o acontecimento histórico como matéria de seus romances; não foi tampouco a mera necessidade de ação ou motivação realista que guiaram a transformação da realidade histórica em ficção romanesca. Ao transformar a História em Literatura, interroga sobre sua finalidade e sobre o verdadeiro sentido da ação histórica individual; dessa interrogação vê-se jorrar toda a tragicidade da experiência humana perante a História (FREITAS, 1986).
\end{abstract}

Para o historiador, trabalhar com a literatura, seja analisando uma obra que trata da cidade, como tão bem o fez Walter Benjamin (1989) ao visitar a poética de Charles Baudelaire, ou analisando a produção de Lima Barreto, Jorge Amado, Jorge Luís Borges, Gabriel García Marques, Frederico García Lorca, Carlos Fuentes ou Oswald de Andrade, em nossa oficina percebemos que os diferentes momentos históricos não estão aí refletidos de forma expressa e clara, mas foram convertidos em literatura nessas obras de tão grande importância. São, entre outras, excelentes pistas ao historiador. Nessa perspectiva, percebemos a ligação, por exemplo, entre Baudelaire e o contexto urbano de Paris; Jorge Amado e o contexto urbano de Salvador; e ainda Jorge Luís Borges e o contexto urbano de Buenos Aires, entre outros. As particularidades da vida cotidiana são enfocadas pelos autores citados como hábitos pessoais, o colorido das construções, o cenário florido dos jardins, as vielas escuras, as crianças maltrapilhas, as mulheres elegantes, as ruas de comércio, o vestuário e comportamento sócio-moral dos indivíduos.

A obra Suor, de Jorge Amado, que retrata o período vivido pelo autor em meados da década de 1920 em uma pequena rua próxima ao Largo do Pelourinho, em Salvador, BA, é uma narrativa explicativa da riqueza de possibilidades da leitura do social no contexto urbano por meio de um romance. Sem o objetivo de analisarmos profundamente a obra, podemos apenas, com um rápido levantamento dos tipos humanos que compõem o mosaico urbano do número 68 da Rua do Pelourinho, avaliar a extensão dessa imensa riqueza. As prostitutas, os vendedores ambulantes, mendigos, as lavadeiras, os trabalhadores do porto, as costureiras, os moleques de rua etc. Esse vasto universo social ainda não foi totalmente explorado pela historiografia, ou mesmo pela própria literatura anterior a Jorge Amado. A miséria é a tônica, onde a falta de higiene, com ratazanas infestando o ambiente e se misturando aos operários suados, bêbados, às prostitutas, crianças, e o ar contaminado pelo mofo. A questão central do romance é a tensão entre inquilinos proprietários do casarão.

O brilhante literato faz da denúncia uma trama, tematizando a miséria e sujeira, discutindo o processo de higienização das habitações populares de um povo que mora e que se alimenta mal, em consequência de um trabalho miserável. São inúmeras as privações, de modo ser essa população vista de forma negativa no conjunto da sociedade mais privilegiada, enxergando-os como rudes e incivilizados. 
Essas questões colocadas em uma trama literária, da maneira como se expressou o autor, denunciavam a miséria real da região, chocando os seus colegas da elite intelectual não apenas baiana, como nacional e mesmo latino-americana, que se negavam a ver a triste realidade do povo. Era, então, uma tentativa de Jorge Amado em conscientizar a sociedade através dos personagens dessa trama e, ao mesmo tempo, defender e cooptá-la para a sua ideologia política.

1990, passados 56 anos da publicação de Suor, em uma fala a um jornal, Jorge Amado (apud PALAMARTCHUK, 1998) se declarou realista, dizendo que em 1934 apenas apresentou uma proposta literária que rompia com a corrente dos acadêmicos e com os modernistas. $A$ razão de Amado desqualificar essas correntes literárias é, segundo o próprio, "[...] porque elas não contribuíram na luta pelas mudanças nas camadas sociais existentes".

Outro autor que enfocamos neste ensaio é o mexicano Carlos Fuentes, que escreveu O espelho enterrado, obra em que Fuentes aborda com equilíbrio, mas também vigor e paixão, os cinco séculos da conquista e colonização da América pelos espanhóis. Dos espelhos ibéricos de Cervantes e Velásquez aos enterrados em tumbas indígenas no México; da expulsão dos árabes da Espanha ao massacre dos astecas e incas; de El Cid a Simão Bolívar, chegando aos caudilhos, às revoluções e tensões de fronteira entre México e Estados Unidos, esse autor discorre acerca do assombroso jogo de múltiplos reflexos que é a construção da identidade hispano-americana.

Constrói ainda uma ponte entre passado, presente e futuro, destacando uma questão universal para o século XXI: como lidar com o outro? "Ao abraçarmos o outro, não só nos encontramos com nós mesmos, como incluímos em nossa vida e nossa consciência as imagens marginais que o mundo moderno, otimista e progressista condenou ao esquecimento (FUENTES, 2001).

Trata-se de uma obra fundamental de introdução à cultura hispano-americana. São mais de quinhentos anos de acontecimentos históri- cos que compartilhamos com Carlos Fuentes, quem nos apresenta de Dom Quixote de La Mancha, de Cervantes, aos grandes pintores espanhóis - de Goya a Picasso -, passando pelos dramaturgos Lope de Vega e Calderón de La Barca, ao cineasta Luís Buñuel, ao muralista Diego de Rivera, aos escritores José Martí, Juan Rufo, Jorge Luís Borges, Gabriel García Marques a Jose Guadalupe Posada, mexicano que antecipou os grafites modernos, retratando gravuras de assassinatos, sexo, danças e touradas; entre tantos outros nomes e obras.

Dono de um excelente otimismo, bem fundamentado, o escritor expressa que em meio à crise, a América Latina se transformou em uma mobilização social permanente, de baixo para cima, e da periferia para o centro. Alerta ao risco sempre presente de que o Continente chegue a ser dominado por organizações fascistas ou grupos ideológicos brutais, mas confia que ao alcançar o desenvolvimento econômico junto com a democracia e justiça social é uma meta possivel. $O$ espelho enterrado encanta pela descoberta dos vizinhos e pela sensação de que nossas histórias muito se tangenciam. Entrelaçam-se rumo ao mesmo destino. Fuentes pretendeu aí resumir a totalidade da arte hispânica e colocá-la em pé de igualdade à tradição anglo-saxônica. Trata-se de um ensaio que deu origem a um documentário produzido pela BBC de Londres para a televisão. Este, uma belíssima fonte para um historiador interessado e atento.

Da mesma forma que Carlos Fuentes lida com o papel do outro, mas de modo diferenciado, encontramos nas obras de Jorge Luís Borges, literato argentino, o outro no papel de nós mesmos, e nós mesmos como o outro. Trata-se da sublimação do ser, da individualização e, ao mesmo tempo, multiplicação do mesmo. $\mathrm{O}$ eu passado é um, o eu hoje é outro, e o eu amanhã deve ser esquecido, assim como o eu passado.

Gostaríamos de ressaltar que a relação entre história e literatura que aqui nos propomos a discutir perpassa muito da obra de Borges, visto que esse autor traz referências de suas vivências, mas também funde realidade e fantasia, sendo 
ambíguo, difícil para ser classificado, tal como o tenta definir Álvaro Alves de Faria (2001):

\author{
NÃO é Comunista. Não é Nacionalista. \\ Faz questão de dizer que também não é \\ anti-semita \\ Não é nada. Nem escritor.. \\ Borges afirma que ele é feito de duas pessoas. \\ Ele e um outro Borges. \\ Nenhum dos dois vale uma definição.
}

Borges assim expressou, em 1969, no Prólogo à reedição de Fervor de Buenos Aires, o seu primeiro livro - originalmente publicado em 1923 e que a Editora Globo relançou na forma de Obras Completas, em 1999:

Não reescrevi o livro. Mitiguei seus excessos barrocos, limei asperezas, risquei sentimentalismos e imprecisões e, no decurso desse labor às vezes grato e outras vezes incômodo, senti que aquele rapaz que em 1923 o escreveu já era essencialmente que significa essencialmente? - o senhor que agora se resigna ou corrige. Somos o mesmo; os dois descremos do fracasso e do sucesso, das escolas literárias e de seus dogmas... Como os de 1969, os jovens de 1923 eram tímidos. Temerosos de uma intima pobreza, tratavam como agora de escamoteá-la sob inocentes novidades ruidosas. Eu, por exemplo, me propus demasiados fins: arremedar certas fealdades (que me agradavam) de Miguel de Unamuno, ser um escritor espanhol do século XVII, ser Macedonio Fernández, descobrir as metáforas que Lugones já havia descoberto, cantar uma Buenos Aires de casas baixas e, para o poente ou para o Sul, de chácaras gradeadas.

Naquele tempo, procurava os entardeceres, os arrabaldes e a desdita; agora, as manhãs, o centro e a serenidade.

J. L. B. Buenos Aires, 18 de agosto de 1969 (BORGES, 1999a).

Essa obra que ora nos inspira a trazer para análise neste artigo é escrita por Borges no seu retorno a Buenos Aires, aos 23 anos de idade, após uma estadia de quase dez anos na Suíça, acompanhando o pai doente, vítima da mesma enfermidade degenerativa oftalmológica que veio mais tarde também a cegar o próprio autor (BORGES, 2000). Nesse livro de poesias, Borges retrata o seu encantamento com a cidade "nova" que descobriu, depois de a ter deixado. É um deslumbramento e uma paixão pela cidade que o viu nascer, e que se modernizou nesse período de ausência. Retratá-la para Borges nessa época de sua juventude é algo necessário.
A volta
Ao cabo dos anos de desterro
voltei à casa de minha infância
e ainda me é alheio o seu âmbito.
Minhas mãos tocaram as árvores
como quem acaricia alguém que dorme
e repeti antigos caminhos
como se recobrasse um verso esquecido
e vi ao espalhar da tarde
a frágil lua nova
que se achegou ao amparo sombrio
da palmeira de folhas altas,
como ao seu ninho o pássaro.
Que caterva de céus
abarcará entre suas paredes o pátio,
quantos heróicos poentes
militarão na profundeza da rua
e quantas quebradiças luas novas
infundirão ao jardim sua ternura,
antes que volte a reconhecer-me a casa
e de novo seja um hábito! (BORGES, 2000).

Ao longo do tempo e de sua obra, o autor trabalhou o esquecimento - e não mais a memória. Borges nunca trabalhou a memória. $\mathrm{O}$ "esquecer" em Borges é o que o faz ser ele mesmo e, ao mesmo tempo, o outro.
Alguém
Um homem trabalhado pelo tempo, um homem que nem sequer espera a morte
(as provas da morte são estatísticas 
e não há ninguém que não corra o risco

de ser o primeiro imortal),

um homem que aprendeu a agradecer

as modestas esmolas dos dias:

o sonho, a rotina, o sabor da água,

uma não suspeitada etimologia,

um verso latino ou saxão,

a lembrança de uma mulher que o abandonou

já faz tantos anos

que hoje pode recordá-la sem amargura, um homem que não ignora que o presente já é o futuro e o esquecimento,

um homem que foi desleal

e com quem foram desleais

pode sentir de repente, ao cruzar a rua,

uma misteriosa felicidade

que não vem do lado da esperança

mas sim de uma antiga inocência,

de sua própria raiz ou de um deus disperso.

Sabe que não deve olhá-la de perto,

porque há razões mais terriveis que tigres

que the demonstrarão seu dever

de ser um desventurado,

porém humildemente recebe

essa felicidade, esse lampejo.

Talvez na morte para sempre sejamos,

quando o pó for pó,

essa indecifrável raiz,

da qual para sempre crescerá,

equânime ou atroz,

nosso solitário céu ou inferno (BORGES, 1999b).

Por meio de Borges e Fuentes, entre tantos outros autores latino-americanos, observamos certa tradição em trabalhar com a ideia de espelhos e labirintos para traçar o processo histórico da América Latina e suas próprias vivências, tal como nos demonstra Gomes Jr. (1991), em seu ensaio - na conferência O pesadelo, publicada em Sete noites -, quando Borges diz que os seus pesadelos são sempre os mesmos. De um lado, temos o labirinto e, de outro, o espelho; comumente, os dois se confundem: afinal, "[...] bastam dois espelhos opostos para construir um labirinto" (GOMES JR, 1991).

Na obra da professora de Comunicação da PUC-RJ, Vera Lúcia Follain Figueiredo (1994),
Da profecia ao labirinto, ao se deter na análise de Gabriel Garcia Marques, reforçando a ideia de labirinto na América, temática que nos interessa neste artigo, chama à atenção a epígrafe que antecipa o quinto capítulo, onde Borges é citado para justificar o emprego dessa expressão. Para o escritor argentino, o labirinto é um símbolo que o deixa perplexo e que o acompanhou durante toda a vida, fazendo com que muitos de seus próprios atos fossem inexplicáveis. Para Borges, é como um edifício construído propositalmente para que alguém se perca. Não resta dúvida de que, na América, os espelhos refletidos geram não pinturas como As meninas, de Velázquez, mas imensos labirintos onde os habitantes do Continente se assustam, perdem-se e se assombram. Forte enigma que tanto a literatura quanto a história devem estar atentas e aparelhadas para oferecer uma compreensão acurada das vicissitudes de um cotidiano repleto de surpresas, mudanças e historicidade.

Ainda dentro da mesma linha de pensamento - sobre espelhos e labirintos na construção do olhar da América Latina -, debruçamo-nos também sobre Gabriel José García Márquez, ou apenas Gabo aos amigos. Esse colombiano escreveu O general em seu labirinto, romance baseado na figura de Simón Bolívar, chamado de o "libertador dos movimentos pró-independência da América Latina". No ano de 2010 a América Latina comemorou os seus duzentos anos de emancipação, graças a Bolívar e a outros heróis. Vários foram os encontros, simpósios, seminários e as festividades de comemoração a esse segundo centenário de independência.

O título dado ao romance nos sugere o oposto da ideia de liberdade, referindo-se à dificuldade de o general achar uma saída, nos caminhos tortuosos em que se encontrava. A representação do general, o libertador que aí aparece, não é a de um forte e garboso militar criollo em ação, mas a de um corpo frágil, inerte, boiando em uma banheira. É uma cena dramática, impregnada da figura da morte, que perpassa todo o romance. Quis o autor mostrar uma América que emerge das cinzas 
da morte. O protagonista da independência da América em García Márquez, antes de ser um belo e grande herói, é a própria América, que renasce da morte dos seus povos e de seus projetos abortados - mais próxima do labirinto do que do caminho glorioso dos vencedores (FIGUEIREDO, 1994). Nessa obra, o autor retrata os últimos dias de Simón Bolívar e a sua viagem pelo Rio Magdalena, em direção à Cartagena, indo para a Europa - decidiu o destino que morresse ao chegar à Santa Marta, lugar de onde saiu para libertar a América.

Ao compor esse romance, García Márquez se baseou na leitura das cartas reais, escritas nessa viagem por Bolivar - trata-se do romancista imitando o historiador e buscando a base documental para a sua narrativa. Encontrou o literato o que o historiador nunca perquiriu e, portanto, nunca trabalhou nas últimas cartas escritas pelo libertador - caso emblemático da literatura ajudando a história.

Nas páginas do romance latino-americano desfilam os expoentes de toda uma estrutura de dominação: políticos, velhos aristocratas, oportunistas recém-chegados, fazendeiros truculentos, funcionários públicos subservientes, advogados venais, representantes do capitalismo local, dominados e dominantes. Os vários escritores latino-americanos nos mostram as ditaduras em sua insanidade grotesca, lutas das classes populares, repressões cruentas. Revelam-nos o pânico dos dominados diante da burocracia emperrada e incompreensível e, por isso mesmo, instrumento de sujeição. Evidenciam-nos também o pânico dos grupos dominantes, no fundo, conscientes da fragilidade de toda essa estrutura e da ameaça permanente de uma ruptura social. Apresentam-se as turbulências do real e imaginário, utilitário e mágico, da dúvida e perplexidade, memória e esperança, do esquecimento e da desesperança, do espelho e labirinto.

Por razões como essas é que aceitamos, utilizamos, propagamos e desvelamos o significado da literatura como fonte aos trabalhos do historiador.

\section{Referências}

ARISTÓTELES. Poética nona. In: Arte retórica e arte poética. Rio de Janeiro: Ediouro, [20--?]

AVELINO, Y. D. et al. O bosque sagrado e o borrador. Projeto História, São Paulo, n. 8-9, p. 8, mar. 1992.

BARTHES, R. Novos ensaios críticos. O grau zero da escritura. São Paulo: Cultrix, 1972

BENJAMIN, W. Charles Baudelaire. Um lírico no auge do capitalismo. In: Obras escolhidas. v. 3. São Paulo: Brasiliense, 1989.

BORGES, J. L. Um ensaio autobiográfico (18991970). São Paulo: Globo, 2000

Fervor de Buenos Aires. In: Obras completas. v. 1. São Paulo: Globo, 1999a

O outro, o mesmo. In: Obras completas. v. 2. São Paulo: Globo, 1999b.

CARDOSO, C. F.; VAINFAS, R. Domínios da História. Rio de Janeiro: Campus, 1997.

CARVALHO, C. de. Para compreender Saussure. Petrópolis, RJ: Vozes, 2003

CERVANTES, M. de. Dom Quixote de La Mancha. Porto Alegre, RS: L\&PM Pocket, 2005.

DEELY, J. Semiótica básica. São Paulo: Ática, 1990.

ELEUTÉRIO, M. de L. Oswald de Andrade, o itinerário de um homem sem profissão. Campinas, SP: Unicamp, 1987.

FARIA, Á. A. de. Borges. O mesmo e o outro. São Paulo: Escrituras, 2001.

FIGUEIREDO, V. L. F. de. Gabriel García Marques: a história como labirinto. In: Da profecia ao labirinto. Imagens da história na ficção latino-americana contemporânea. Rio de Janeiro: Imago, 1994

FREITAS, M. T. de. Literatura e história: o romance revolucionário de André Malraux. São Paulo: Atual, 1986. FREYRE, G. Casa grande e senzala. Rio de Janeiro: José Olympio, 1967.

FUENTES, C. O espelho enterrado. Reflexões sobre a Espanha e o Novo Mundo. Rio de Janeiro: Rocco, 2001

GOMES JR, G. S. Borges. Disfarce de autor. São Paulo: Educ, 1991

LACAPRA, D. História e romance. Revista de História da Unicamp, Campinas, SP, n. 2-3, p. 107-124, 1991. 
PALAMARTCHUK, A. P. Jorge Amado: um escritor de putas e vagabundos? In: CHALHOUB, S., PEREIRA, L. A. de M. (Org.). A história contada. Capítulos de história social da literatura no Brasil. Rio de Janeiro: Nova Fronteira, 1998.

SANTAELLA, L. Matrizes da linguagem e pensamento. São Paulo: Iluminuras, 2001.

SEVCENKO, N. Literatura como missão. São Paulo: Brasiliense, 1995.
SOUSA, A. P. Tensões do tempo. A saga do cacau na ficção de Jorge Amado. Ilhéus, BA: Editus, 2001.

VEYNE, P. M. Como se escreve a História. Brasília, DF: UNB, 1995.

O objeto da História. In: Foucault revoluciona a história. Brasília, DF: UnB, 1982. 
